\section{ADOLESCENTES E CONDUTA INFRACIONAL: ESPAÇOS, EQUIPAMENTOS E CONTEÚDOS DE ESPORTE E LAZER}

\author{
ADOLESCENTS AND INFRACTION CONDUCT: SPORT AND LEISURE \\ SPACES, EQUIPMENT AND CONTENT C
}

ADOLESCENTES Y CONDUCTA INFRACTORA: ESPACIOS, EQUIPOS Y CONTENIDOS DE DEPORTE Y RECREACIÓN Cे

doi' $h$ ttps://doi.org/10.22456/1982-8918.102733

iD Ueliton Peres de Oliveira*<uelitonoliveira@sesp.mt.gov.br>

Willian Lazaretti da Conceição** <lazaretti@ufpa.br>

José Tarcísio Grunnenvaldt* <jotagrun@hotmail.com>

Raul Angel Carlos Olivera*** <raulcarlos@unemat.br>

Riller Silva Reverdito*** <rsreverdito@unemat.br>

\footnotetext{
*Universidade Federal de Mato Grosso. Cuiabá, MT, Brasil.

**Universidade Federal do Pará. Belém, PA, Brasil.

***Universidade do Estado de Mato Grosso (UNEMAT). Cáceres, MT, Brasil.
}

Resumo: Este estudo exploratório e descritivo tem por objetivo identificar os espaços, equipamentos e conteúdos de esporte e lazer de um município do estado de Mato Grosso, com maior incidência de adolescentes em cumprimento de medida socioeducativa de internação nos anos de 2017 e 2018. Os dados foram disponibilizados pela Gestão Estadual do Sistema de Informação para Infância e Adolescência (SIPIA). Realizaram-se observações in loco em oito bairros, utilizando categorias de análise predefinidas para registros em diário de campo. Os resultados demonstram a escassa oferta de espaços, equipamentos e conteúdos de esporte e lazer disponibilizados aos adolescentes dessas comunidades. Diante desse cenário, a falta de acesso às políticas de esporte e lazer pode configurar como possível fator de risco ao cometimento de ato infracional no contexto pesquisado, além da exposição dos jovens ao mesmo risco ao retornarem à comunidade.

Palavras chave: Adolescente. Esportes. Atividades de Lazer. Defesa da criança e do adolescente.
Recebido em: 06-05-2020 Aprovado em: 01-09-2020 Publicado em: 07-12-2020

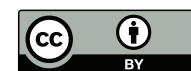

Este é um artigo publicado sob a licença Creative Commons Atribuição 4.0 Internacional (CC BY 4.0). elSSN: $1982-8918$ 


\section{INTRODUÇÃO}

A adolescência é uma fase da vida marcada por mudanças significativas no campo da formação identitária do sujeito, haja vista o processo de desenvolvimento nas relações humanas. Reconhecer a construção histórica e cultural que permeia as trajetórias de adolescentes é fulcral para contrapor a invisibilidade social à qual estão expostos (FEIJÓ; ASSIS, 2004; OLIVEIRA; TURECK, 2019; KOSTULSKI et al., 2019). Entretanto, observa-se há décadas um processo de estigmatização da população jovem advinda de contextos de vulnerabilidade social (MORAIS; RAFFAELLI; KOLLER, 2012; COSCIONI et al., 2019; KOSTULSKI et al., 2019), bem como a tendência de concentrar o fenômeno da violência em um grupo específico da sociedade, considerando o modus operandi do Estado ante as questões relacionadas ao adolescente autor de ato infracional (JIMENEZ; FRASSETO, 2015).

De acordo com o Estatuto da Criança e Adolescente (ECA) (BRASIL, 1990, Art. 103), "Considera-se ato infracional a conduta descrita como crime ou contravenção penal". O ECA ainda estabelece que os menores de dezoito anos são penalmente inimputáveis, sujeitos a aplicação das medidas socioeducativas previstas no 'Art. 101' do mesmo dispositivo jurídico. O Relatório Anual do Sistema Nacional de Atendimento Socioeducativo (SINASE) de 2017, elaborado pela Secretaria Nacional dos Direitos da Criança e do Adolescente, indica que no Brasil 143.316 mil adolescentes cumpriam medida socioeducativa à época (BRASIL, 2019). E, destes, apenas 24.803 cumpriam medidas socioeducativas de restrição e privação de liberdade. Quanto aos atos infracionais praticados pelos adolescentes, o Relatório enfatiza que a minoria é contra a vida, prevalecendo aqueles de menor poder ofensivo que atentam contra o patrimônio.

O entendimento dos fatores de risco relacionados à conduta infracional de adolescentes é multidimensional, mobilizando áreas distintas da ciência. Estudos têm apontado variáveis relacionadas ao contexto familiar (FEIJÓ; ASSIS, 2004; DIB; BAZON; SILVA, 2012; NUNES; ANDRADE; MORAIS, 2013), aspectos escolares/ evasão (GALLO; WILLIAMS, 2008; BAZON; SILVA; FERRARI, 2013; SILVA; BAZON, 2015; FRANCO; BAZON, 2019), fatores socioeconômicos (OLIVERA; OLIVEIRA, 2019), uso de drogas (MARTINS; PILLON, 2008; JIMENEZ; ANDRADE; BIANCHINI, 2016) e aspectos contextuais relacionados à invisibilidade do adolescente frente às políticas de atendimento primário (ASSIS; CONSTANTINO, 2005; GALLO; WILLIAMS, 2005; JUNQUEIRA; JACOBY, 2006; TEJADAS, 2008; NARDI; DELL'AGLIO, 2010; MARUSCHI; ESTEVÃO; BAZON, 2014; JIMENEZ; MARQUES, 2018; OLIVEIRA; TURECK, 2019). Em suma, os estudos apontam que essas variáveis devem ser analisadas de forma contextualizada, por se tratar de um conjunto de fatores associados ao cometimento de ato infracional.

Nesta esteira, dos fatores de risco relacionados à conduta infracional, observase ainda a inércia do poder público frente às políticas de esporte e lazer para a população jovem do país, mesmo que garantidas no texto Constitucional (BRASIL, 1988). É sabido que o acesso a essas práticas, a partir de conteúdos que considerem esses fenômenos como vias e objetos de educação, propiciam ambientes favoráveis ao desenvolvimento humano, seja em espaços formais, seja em espaços não 
formais (LEONARDI et al., 2014; MACHADO; GALATTI; PAES, 2015). Em relação ao adolescente em conflito com a lei, estudos realizados em contextos de medidas socioeducativas, os quais tomaram o esporte e o lazer como objetos de intervenção (SANIOTO, 2005; SILVA et al., 2008; CONCEIÇÃO, 2012; TIELLET et al., 2017), observaram aspectos positivos por parte dos adolescentes inseridos nas atividades (engajamento, cidadania, autonomia, sociabilização, autoimagem, valores éticos e morais), propiciando o exercício reflexivo dos sujeitos em relação às suas trajetórias e modos de vida.

Para que os sujeitos possam vivenciar diversificadas práticas de esportes e usufruir dos diferentes interesses que contemplam os conteúdos do lazer (artísticos, intelectuais, físicos, manuais, turísticos e sociais) apontados por Marcellino (1996), há de se considerar, antes de tudo, a oferta de espaços e equipamentos que propiciem o acesso democrático à população (MARCELLINO; BARBOSA; MARIANO, 2006) e garantam o acesso e permanência dos jovens nos ambientes esportivos (REVERDITO, 2016; MORAES et al., 2017). Contudo, estudos têm sinalizado para a escassa oferta dessas políticas na trajetória de adolescentes em conflito com a lei (CARNEIRO et al., 2016; TIELLET et al., 2017) e, em outros casos, somente após adentrarem a medida socioeducativa são oportunizados aos espaços, equipamentos e conteúdos esportivos e de lazer (OLIVEIRA et al., 2020).

Diante do exposto, a falta de acesso às políticas de esporte e lazer na trajetória de adolescentes em conflito com a lei tem se configurado como possível fator de risco ao cometimento de ato infracional. Porém, a literatura carece de estudos que investiguem in loco a oferta dessas políticas públicas nos contextos de onde são advindos esses sujeitos. Nesse sentido, este estudo objetivou identificar os espaços, equipamentos e conteúdos de esporte e lazer em comunidades/regiões de um município do estado de Mato Grosso, com maior incidência de adolescentes em cumprimento de medida socioeducativa de internação nos anos de 2017 e 2018. Espera-se que os resultados ofereçam subsídios ao poder público no que tange à elaboração de políticas preventivas direcionadas ao adolescente em situação de vulnerabilidade social.

\section{METODOLOGIA}

\subsection{TIPO DE PESQUISA E CONTEXTO}

Trata-se de um estudo exploratório e descritivo de abordagem qualitativa, realizado através de observação in loco e anotações em diário de campo (GIL, 2008). Os focos de análise da observação foram predefinidos a partir do que se propôs a investigar neste estudo (espaços, equipamentos e conteúdos de esporte e lazer), disponibilizados pelo poder público nos bairros de Cuiabá com maior incidência de adolescentes em cumprimento de medida socioeducativa de internação nos anos de 2017 e 2018.

Cuiabá é um município brasileiro e capital do estado de Mato Grosso, localizado na região Centro-Oeste do país. A área urbana do município divide-se em quatro regiões administrativas (Norte, Sul, Leste e Oeste). De acordo com o Censo de 2010, 
realizado pelo Instituto Brasileiro de Geografia e Estatística (IBGE), a população de Cuiabá à época era de 551.098 habitantes, destes, 49.082 correspondiam à população na faixa de 15 e 19 anos. Nos últimos anos houve crescimento populacional modesto, e a população estimada pelo IBGE em 2019 corresponde a 612.547 habitantes.

Além de concentrar as funções político-administrativas, Cuiabá é considerada o principal polo industrial do estado, que, por sua vez, tem sua economia alavancada pela produção e exportação de grãos. Em relação ao Índice de Desenvolvimento da Educação Básica (IDEB), em 2017 apresentava índice acima da média do país (5,6 nos anos iniciais e 4,5 nos anos finais do ensino fundamental). Quanto ao índice de Desenvolvimento Humano (IDH), em 2010 apresentava índice superior à média do país $(0,785)$ (IBGE, 2020).

\subsection{PROCEDIMENTOS PARA COLETA DOS DADOS}

A coleta de dados envolveu três etapas distintas, sendo: levantamento dos bairros de Cuiabá com maior incidência de adolescentes em cumprimento de medida socioeducativa de internação; participação em audiências públicas realizadas pela Secretaria Municipal de Cultura, Esporte e Turismo de Cuiabá; e observações in loco nos bairros. Na primeira etapa, o levantamento dos bairros de onde os adolescentes em cumprimento de medida socioeducativa de internação advinha foi realizado e disponibilizado pela Gestão Estadual do SIPIA/SINASE/MT, que detém e operacionaliza os dados desses sujeitos no estado de Mato Grosso. O levantamento abrangeu adolescentes dos Centros de Atendimento Socioeducativo de Internação Masculina e Feminina da capital, chegando ao quantitativo de 80 adolescentes internos no período pesquisado. Foram selecionados oito bairros com maior incidência, o que representa $41,25 \%$ da amostra total.

Para a segunda etapa, houve reunião previamente agendada com membros da Secretaria Municipal de Cultura, Esporte e Turismo de Cuiabá, responsáveis pela elaboração do "Plano Municipal de Esporte e Lazer" do município, através do mapeamento dos espaços, equipamentos e projetos de esporte e lazer, validado pelos presidentes de bairro em audiências públicas realizas nas quatro regionais da capital. Assim, participou-se das audiências públicas que ocorreram entre os meses de agosto e novembro de 2019, com a finalidade de comparar os dados que seriam coletados nas observações in loco nos bairros.

A terceira etapa ocorreu concomitantemente à etapa anterior. A priori, foi realizado contato via telefone com os líderes comunitários (presidentes e vicepresidentes de bairros, conselheira tutelar e membros das associações de moradores), a fim de verificar a disponibilidade em acompanhar as observações in loco, por entender que são conhecedores de sua comunidade, atribuindo maior fidedignidade à coleta dos dados. As visitas foram previamente agendadas e ocorreram entre os meses de novembro e dezembro de 2019, em diferentes dias da semana, no período matutino e vespertino, considerando a disponibilidade dos líderes comunitários, que acompanharam o pesquisador nas observações in loco. O deslocamento pelos bairros aconteceu de carro e, em certas situações, o percurso foi realizado caminhando. Nos registros, também foram considerados os espaços e equipamentos disponibilizados às comunidades pelas Escolas Municipais e Estaduais. 
A pesquisa foi submetida ao Comitê de Ética em Pesquisa da Universidade Federal de Mato Grosso - CEP/SAÚDE/UFMT (CAAE: 03382918.9.0000.8124) e aprovada no dia 26 de dezembro de 2018 (Parecer $n^{\circ} 3.102 .411$ ).

\subsection{ANÁLISE DOS DADOS}

Para a análise dos dados consideraram-se as fases de descrição, classificação e interpretação (SAMPIERI; COLLADO; LUCIO, 2006). Quanto à caracterização dos espaços e equipamentos, este estudo parte do entendimento de que os espaços servem como suporte para os equipamentos, ao passo que os equipamentos são objetos que organizam os espaços para atender determinadas atividades específicas (SANTINI, 1993; MARCELLINO et al., 2007a). Em relação ao estado de conservação dos equipamentos, entende-se neste estudo que os "equipamentos em más condições de utilização" são aqueles que não oferecem segurança à prática das atividades por apresentarem falta de manutenção (equipamentos quebrados, enferrujados, depredados e sem limpeza), mas que ainda continuam sendo utilizados pela comunidade. Por "equipamentos abandonados", consideraram-se aqueles que estão em desuso pela comunidade, por não apresentarem condições mínimas de utilização, considerando os aspectos elencados anteriormente. Em relação aos conteúdos, compreendemos como os bens culturais desenvolvidos nesses espaços, que tenham como interesse (objetivo) contemplar o esporte e lazer (MARCELLINO, 2010).

\section{RESULTADOS E DISCUSSÃO}

A partir do levantamento realizado pela Gestão do SIPIA/SINASE/MT, chegouse a dois bairros por região de Cuiabá com maior incidência de adolescentes em cumprimento de medida socioeducativa de internação (Quadro 1). Esse resultado evidencia que a problemática relacionada ao cometimento de ato infracional está presente em diferentes regiões da Capital. Dos oito bairros que compõem a pesquisa, quatro estão localizados em regiões periféricas de Cuiabá (Novo Paraíso II, Osmar Cabral, Tijucal e Jardim Vitória) e outros quatro em regiões centrais da Capital (Alvorada, Carumbé, Dom Aquino e Santa Isabel). Mesmo observando que metade dos bairros investigados está localizada em regiões centrais, foi possível constatar que dentro dos próprios bairros existem suas regiões periféricas, apontadas pela comunidade como locais de maiores índices de criminalidade. A média populacional desses bairros, considerando o Censo realizado pelo IBGE/2010, perfaz um quantitativo de $11,23 \%$ da população total de Cuiabá, estimada pelo IBGE em 2019 (Quadro 1, na próxima página).

Outro fato que chama atenção éo número reduzido de escolas estaduais quando comparado com o de escolas municipais nesses bairros. As escolas municipais, em suma, ofertam a escolarização somente até os anos finais do ensino fundamental. Às escolas estaduais compete a oferta da escolarização inerente ao ensino médio que, em tese, enquadraria parte dos sujeitos pesquisados. Desta forma, os adolescentes veem-se obrigados a se deslocarem para outros bairros distantes de sua comunidade 
para cursar o ensino médio, o que se configura em uma problemática, considerando que a quebra de vínculo escolar tem sido apontada como fator influenciador à evasão escolar desses sujeitos (BAZON; SILVA; FERRARI, 2013; FRANCO; BAZON, 2019).

Quadro 1 - Caracterização dos bairros investigados

\begin{tabular}{|c|c|c|c|c|c|}
\hline Bairro & Região & $\begin{array}{c}\text { Média de } \\
\text { Habitantes }\end{array}$ & $\begin{array}{c}\text { Escolas } \\
\text { municipais }\end{array}$ & $\begin{array}{c}\text { Escolas } \\
\text { estaduais }\end{array}$ & $\begin{array}{c}\% \text { de } \\
\text { incidência }\end{array}$ \\
\hline Novo Paraíso II & Norte & 5.655 & - & - & $8,75 \%$ \\
\hline Dom Aquino & Leste & 10.973 & 1 & 3 & $6,25 \%$ \\
\hline Carumbé & Leste & 2.144 & 2 & - & $5 \%$ \\
\hline Osmar Cabral & Sul & 4.530 & 3 & - & $5 \%$ \\
\hline Tijucal & Sul & 15.334 & - & 4 & $5 \%$ \\
\hline Alvorada & Oeste & 13.035 & 1 & - & $3,75 \%$ \\
\hline Jardim Vitória & Norte & 8.966 & 3 & - & $3,75 \%$ \\
\hline Santa Isabel & Oeste & 8.213 & 2 & - & $3,75 \%$ \\
\hline TOTAL & & $\mathbf{6 8 . 8 5 0}$ & $\mathbf{1 2}$ & $\mathbf{7}$ & $\mathbf{4 1 , 2 5 \%}$ \\
\hline
\end{tabular}

Fonte: Elaborado pelos autores.

Em relação às incidências, se somados os números por região administrativa, não há disparidade considerável. Entretanto, é possível observar um número inferior na região Oeste. Quando somados e comparados os índices dos bairros localizados em regiões periféricas e centrais da capital, foi possível identificar maior incidência nos bairros periféricos ( $n=22,5 \%$ ) em relação aos bairros localizados em regiões centrais $(n=18,75)$. Contudo, também não houve disparidade entre os resultados, indicando que no caso investigado, estar inserido em regiões periféricas não se configurou como fator preponderante à conduta infracional. Desta forma, há de se considerar que os fatores de risco e proteção em diferentes contextos de vulnerabilidade social dependem das relações e reciprocidade que tais ambientes propiciam aos sujeitos, possibilitando a superação das adversidades e a reflexão sobre os modos de vida (POLETTO; KOLLER, 2008; MORAIS; RAFFAELLI; KOLLER, 2012).

O levantamento e caracterização dos espaços, equipamentos e conteúdos de esporte e lazer disponibilizados nos bairros investigados foram sumarizados, conforme Quadro 2. Os dados sinalizam que a oferta de espaços $(n=46)$, se comparada com a média de habitantes residentes nas comunidades $(n=68.850)$, é insuficiente quanto à quantidade, sendo tanto nos bairros periféricos $(n=20)$, que apresenta média populacional de 34.485 habitantes, como nas regiões centrais $(n=26)$, com média populacional de 34.365 habitantes. Quanto ao estado de conservação, tornam-se insatisfatórios no que tange às más condições de utilização de alguns equipamentos $(n=10)$, havendo outros em total estado de abandono $(n=4)$. Dos equipamentos em más condições de utilização e abandonados, a maioria está localizada em bairros das regiões periféricas de Cuiabá ( $n=09$ ), o que corrobora outros estudos que sinalizam para a mesma problemática relacionada à escassez dessas políticas públicas e a "centralização" dos equipamentos em grandes cidades (MARCELLINO; BARBOSA; MARIANO, 2006; MARCELLINO et al., 2007a; ANDRADE; MARCELLINO, 2011; REVERDITO et al., 2012). (Ver Quadro 2) 
Quadro 2 - Relação dos espaços, equipamentos e conteúdos de esporte e lazer

\begin{tabular}{|c|c|c|c|c|c|}
\hline Bairros & Espaços públicos & QTD. & Caracterização dos equipamentos & Conteúdos & Observações do pesquisador \\
\hline Paraíso II & Campo de Futebol & 1 & $\begin{array}{l}\text { Campo de terra batida em más condições de uso/Balizas } \\
\text { para futebol e refletores. }\end{array}$ & - & - \\
\hline \multirow{11}{*}{$\begin{array}{l}\text { Dom } \\
\text { Aquino }\end{array}$} & $\begin{array}{l}\text { Complexo esportivo } \\
\text { e de lazer }\end{array}$ & 1 & $\begin{array}{l}\text { Contém ginásio poliesportivo, campo de futebol, futebol } \\
\text { society e de areia, quadra coberta, pista de atletismo e } \\
\text { quadra de vôlei de areia/ Boas condições de uso. }\end{array}$ & $\begin{array}{l}\text { Tênis de Mesa } \\
\text { - Federação } \\
\text { Matogrossense de } \\
\text { Tênis de Mesa. }\end{array}$ & $\begin{array}{l}\text { O complexo é utilizado em sua } \\
\text { maioria por adultos, de vários } \\
\text { bairros de Cuiabá. }\end{array}$ \\
\hline & Miniestádio & 1 & $\begin{array}{l}\text { Gramado, balizas para futebol e redes em más condições } \\
\text { de uso/refletores queimados/alambrado e arquibancada } \\
\text { sem conservação. }\end{array}$ & $\begin{array}{l}\text { Projeto de Futebol: } \\
\text { 'Perto da Bola longe } \\
\text { das Drogas'. }\end{array}$ & $\begin{array}{l}\text { Realizado por voluntário ex- } \\
\text { atleta, sem vínculo com poder } \\
\text { público. }\end{array}$ \\
\hline & Campo de futebol & 1 & $\begin{array}{l}\text { Gramado, balizas, redes e refletores em boas condições } \\
\text { de uso. }\end{array}$ & - & - \\
\hline & $\begin{array}{l}\text { Campo de futebol } \\
\text { society }\end{array}$ & 2 & $\begin{array}{l}\text { Gramado em más condições de uso/Balizas, alambrado e } \\
\text { refletores em condições de uso. }\end{array}$ & - & - \\
\hline & Ginásio poliesportivo & 1 & $\begin{array}{l}\text { Cobertura, piso, balizas, redes, refletores e } \\
\text { arquibancadas em boas condições de uso/Sem } \\
\text { equipamentos para prática de basquete e vôlei. }\end{array}$ & $\begin{array}{l}\text { Futsal - Programa } \\
\text { 'Bom de Bola bom de } \\
\text { Escola' - Secretaria } \\
\text { Municipal de } \\
\text { Educação. }\end{array}$ & $\begin{array}{l}\text { O programa atende alunos da } \\
\text { Rede Municipal de Ensino entre } \\
6 \text { a } 14 \text { anos/Poucos alunos são } \\
\text { adolescentes. }\end{array}$ \\
\hline & Quadra coberta & 1 & $\begin{array}{l}\text { Cobertura, piso, balizas, redes, refletores e } \\
\text { arquibancadas em boas condições de uso/Sem } \\
\text { equipamentos para prática de basquete e vôlei. }\end{array}$ & - & - \\
\hline & Quadra descoberta & 2 & Balizas para prática de futsal. & - & - \\
\hline & $\begin{array}{l}\text { Campo de futebol de } \\
\text { areia }\end{array}$ & 1 & Balizas, alambrado e refletores. & - & - \\
\hline & $\begin{array}{l}\text { Quadra de vôlei de } \\
\text { areia }\end{array}$ & 1 & Arquibancada e mastro de vôlei sem rede. & - & - \\
\hline & Pista de atletismo & 1 & $\begin{array}{l}\text { Pista com brita e iluminada, em bom estado de } \\
\text { conservação. }\end{array}$ & - & - \\
\hline & $\begin{array}{c}\text { Praça com } \\
\text { equipamentos de } \\
\text { ginástica ao ar livre }\end{array}$ & 2 & $\begin{array}{l}\text { Pouca diversificação dos equipamentos/Bom estado de } \\
\text { conservação. }\end{array}$ & - & - \\
\hline
\end{tabular}

Continua na próxima página...

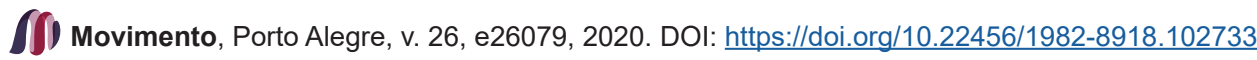


Ueliton Peres de Oliveira et al.

Continuação do quadro 2

\begin{tabular}{|c|c|c|c|c|c|}
\hline & PM/ROTAM/MT & 1 & $\begin{array}{l}\text { Espaço com tatame ampliado, proteção de parede e } \\
\text { cobertura. }\end{array}$ & $\begin{array}{l}\text { Jiu-jítsu - 'Projeto } \\
\text { Formando Cidadãos'. }\end{array}$ & $\begin{array}{l}\text { Realizado por Policiais } \\
\text { Militares. }\end{array}$ \\
\hline & $\begin{array}{l}\text { Biblioteca municipal } \\
\text { 'Saber com Sabor' }\end{array}$ & 1 & Espaços para leitura e demais atividades culturais. & $\begin{array}{l}\text { Leitura e atividades } \\
\text { culturais. }\end{array}$ & $\begin{array}{l}\text { Profissionais da Secretaria } \\
\text { Municipal de Educação. }\end{array}$ \\
\hline \multirow{5}{*}{$\begin{array}{l}\text { Osmar } \\
\text { Cabral }\end{array}$} & Miniestádio & 1 & $\begin{array}{l}\text { Gramado, alambrado, balizas, refletores e vestiários em } \\
\text { más condições de uso/Passará por revitalização. }\end{array}$ & $\begin{array}{l}\text { Projeto de Futebol aos } \\
\text { finais de semana. }\end{array}$ & $\begin{array}{l}\text { Realizado por voluntário ex- } \\
\text { atleta. }\end{array}$ \\
\hline & Ginásio poliesportivo & 1 & $\begin{array}{l}\text { Estrutura em condições para prática de futsal/ Falta de } \\
\text { equipamentos para prática de modalidades como o vôlei } \\
\text { e basquete. }\end{array}$ & - & Utilizado em suma por adultos. \\
\hline & Quadra coberta & 1 & $\begin{array}{l}\text { Escola Municipal /Balizas, mastros de vôlei, tabela de } \\
\text { basquete, refletores e arquibancada em condições de } \\
\text { uso. }\end{array}$ & $\begin{array}{l}\text { Aulas de Educação } \\
\text { Física Escolar. }\end{array}$ & $\begin{array}{l}\text { A faixa etária atendida na } \\
\text { Escola Municipal destoa do } \\
\text { público investigado. }\end{array}$ \\
\hline & Quadra descoberta & 1 & Em desuso/Passará por reforma. & - & Escola em reforma. \\
\hline & $\begin{array}{l}\text { Biblioteca municipal } \\
\text { 'Saber com Sabor' }\end{array}$ & 1 & Espaços para leitura e demais atividades culturais. & $\begin{array}{l}\text { Leitura e atividades } \\
\text { culturais. }\end{array}$ & $\begin{array}{l}\text { Profissionais da Secretaria } \\
\text { Municipal de Educação. }\end{array}$ \\
\hline \multirow{4}{*}{ Tijucal } & Miniestádio & 1 & Abandonado a mais de dois anos/Tomado pelo matagal. & - & - \\
\hline & Ginásio poliesportivo & 1 & $\begin{array}{l}\text { Cobertura, refletores, baliza de futsal, redes das balizas, } \\
\text { arquibancadas em condições de uso/Sem tabela de } \\
\text { basquete e mastro para vôlei. }\end{array}$ & $\begin{array}{l}\text { Projeto de Futsal e } \\
\text { Handebol//dade entre } \\
7 \text { e } 17 \text { anos/Secretaria } \\
\text { de esportes. } \\
\end{array}$ & $\begin{array}{l}\text { Reformas e manutenções do } \\
\text { ginásio são realizadas pela } \\
\text { comunidade/Utilizado em suma } \\
\text { pelos adultos. }\end{array}$ \\
\hline & Quadra coberta & 4 & $\begin{array}{l}\text { Escolas Estaduais/Cobertura, refletores e balizas de } \\
\text { futsal em condições de uso/ Sem tabela de basquete e } \\
\text { mastro para vôlei. }\end{array}$ & $\begin{array}{l}\text { Aulas de Educação } \\
\text { Física. }\end{array}$ & $\begin{array}{l}\text { Após o período de aula as } \\
\text { Escolas abrem espaço na } \\
\text { quadra para os jovens da } \\
\text { comunidade, contudo sem } \\
\text { orientação profissional. }\end{array}$ \\
\hline & Quadra descoberta & 1 & $\begin{array}{l}\text { Localizada na praça do bairro/Cercada de tela/Balizas } \\
\text { para futsal em condições de uso/Sinais de depredação, } \\
\text { inclusive nas tabelas de basquete e refletores. }\end{array}$ & - & $\begin{array}{l}\text { Utilizada por jovens da } \\
\text { comunidade, sem orientação } \\
\text { profissional. }\end{array}$ \\
\hline
\end{tabular}

Continua na próxima página...

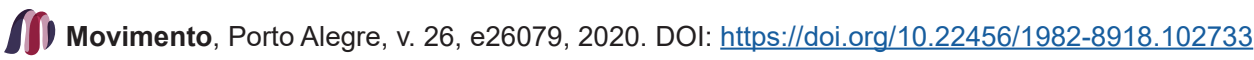


Continuação do quadro 2 .

\begin{tabular}{|c|c|c|c|c|c|}
\hline \multirow{3}{*}{ Alvorada } & Quadra coberta & 1 & $\begin{array}{l}\text { Escola Municipal/Balizas para futsal, tabela de basquete } \\
\text { e refletores em condições de uso. }\end{array}$ & $\begin{array}{l}\text { Aulas de Educação } \\
\text { Física. }\end{array}$ & - \\
\hline & Quadra descoberta & 1 & $\begin{array}{l}\text { Localizada em uma praça, cercada, com refletores e } \\
\text { balizas para futsal/ Sem tabela de basquete e mastro } \\
\text { para vôlei. }\end{array}$ & - & $\begin{array}{l}\text { Utilizada por crianças e } \\
\text { jovens da comunidade, sem } \\
\text { orientação profissional. }\end{array}$ \\
\hline & $\begin{array}{c}\text { Praça com } \\
\text { equipamentos de } \\
\text { ginástica ao ar livre }\end{array}$ & 1 & Equipamentos diversificados e novos. & - & Espaço ocioso. \\
\hline \multirow{5}{*}{$\begin{array}{l}\text { Jardim } \\
\text { Vitória }\end{array}$} & Miniestádio & 1 & $\begin{array}{l}\text { Gramado, balizas, refletores, arquibancada em condições } \\
\text { de uso. }\end{array}$ & - & $\begin{array}{l}\text { Utilizados em suma por adultos } \\
\text { As crianças e adolescentes } \\
\text { utilizam as laterais do campo } \\
\text { para jogarem. }\end{array}$ \\
\hline & Quadra coberta & 3 & $\begin{array}{l}\text { Escolas municipais/Duas quadras contendo refletores, } \\
\text { balizas para futsal, tabelas de basquete em condições de } \\
\text { uso/ Uma quadra abandonada. }\end{array}$ & $\begin{array}{l}\text { Duas quadras são } \\
\text { utilizadas para Aulas } \\
\text { de Educação Física. }\end{array}$ & $\begin{array}{l}\text { A quadra abandonada está } \\
\text { localizada ao lado de uma } \\
\text { Escola municipal/Uma estrutura } \\
\text { em potencial inutilizada. }\end{array}$ \\
\hline & Praça & 1 & Minipalco para apresentações culturais. & - & $\begin{array}{l}\text { Apresentações culturais } \\
\text { esporádicas, articuladas pela } \\
\text { própria comunidade. }\end{array}$ \\
\hline & Espaço CUFA & 1 & Abandonado. & - & $\begin{array}{l}\text { O espaço hoje abandonado } \\
\text { já propiciou o acesso a várias } \\
\text { manifestações culturais na } \\
\text { comunidade. }\end{array}$ \\
\hline & Centro comunitário & 1 & Abandonado. & - & - \\
\hline \multirow{5}{*}{$\begin{array}{l}\text { Santa } \\
\text { Isabel }\end{array}$} & Campo de futebol & 1 & Gramado e balizas em condições de uso. & - & $\begin{array}{l}\text { Utilizado em suma para } \\
\text { torneios de adultos. }\end{array}$ \\
\hline & $\begin{array}{l}\text { Campo de futebol } \\
\text { society }\end{array}$ & 2 & $\begin{array}{l}\text { Gramados, balizas, redes das balizas, alambrados e } \\
\text { refletores em boas condições de uso. }\end{array}$ & - & $\begin{array}{l}\text { Utilizado em suma para } \\
\text { torneios de adultos. }\end{array}$ \\
\hline & Quadra coberta & 1 & $\begin{array}{l}\text { Escola Municipal/Piso e balizas de futsal em condições } \\
\text { de uso/Sem tabelas de basquete e mastro para o vôlei. }\end{array}$ & $\begin{array}{l}\text { Aulas de Educação } \\
\text { Física. }\end{array}$ & - \\
\hline & $\begin{array}{c}\text { Praça com } \\
\text { equipamentos de } \\
\text { ginástica ao ar livre }\end{array}$ & 1 & Aparelhos novos de ginástica ao ar livre. & - & Espaço compacto. \\
\hline & $\begin{array}{l}\text { Biblioteca municipal } \\
\text { 'Saber com Sabor' }\end{array}$ & 1 & Espaços para leitura e demais atividades culturais. & $\begin{array}{l}\text { Leitura e atividades } \\
\text { culturais. }\end{array}$ & $\begin{array}{l}\text { Profissionais da Secretaria } \\
\text { Municipal de Educação. }\end{array}$ \\
\hline
\end{tabular}

Fonte: Elaborado pelos autores.

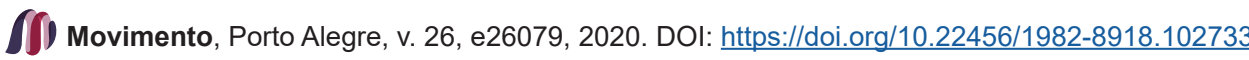


Ao considerar que as trajetórias dos adolescentes em conflito com a lei são marcadas pela defasagem e evasão escolar (DIAS; ONOFRE, 2010; BAZON; SILVA; FERRARI, 2013; SILVA; BAZON, 2015), essa restrita oferta de espaços, equipamentos e conteúdos torna-se ainda maior, visto que uma parcela considerável dos equipamentos identificados nessa pesquisa e reconhecidos na comunidade está inserida nas escolas municipais e estaduais de Cuiabá $(n=12)$. Nesta esteira, o estudo documental de Oliveira et al. (2020) realizado junto a adolescentes em cumprimento de medida socioeducativa de internação no estado de Mato Grosso identificou que $83,83 \%$ dos sujeitos da pesquisa apresentavam histórico de evasão escolar. Os autores constataram que essa problemática restringiu o acesso às práticas de esporte e lazer na trajetória desses adolescentes anterior à aplicação da medida socioeducativa, uma vez que a escola ainda representa um espaço importante para o acesso a tais práticas.

Observou-se a prevalência de equipamentos específicos e conteúdos voltados para a prática dos esportes tradicionais, em especial o futebol e o futsal. Em suma, os espaços ofertados privilegiam os interesses físico-esportivos do lazer (MARCELLINO, 1996), sinalizando para a quase inexistência de outros equipamentos que contemplem seus diferentes conteúdos, ressalva, três bibliotecas públicas que atendem os interesses intelectuais do lazer através da leitura, de suma relevância para esses adolescentes que apresentam significativa defasagem escolar e histórico de evasão. Somam-se a este cenário a escassez de conteúdos disponibilizados nos poucos espaços existentes e o fato de a maioria dos projetos socioesportivos ofertados para os adolescentes serem realizados por voluntários ex-atletas, sem formação específica em Educação Física e/ou áreas afins, bem como projetos sem nenhum vínculo e/ou incentivo do poder público.

Nesse sentido, é fundamental pensar tais práticas mediadas por profissionais capacitados e certos de seu papel político e pedagógico. Ao vislumbrar o alcance educativo que permeia as práticas esportivas, em diferentes contextos e cenários (PIZANI; AMARAL; PAES, 2012; MACHADO; GALATTI; PAES, 2015; REVERDITO, 2016), deve-se considerar a organização, sistematização, aplicação e avaliação de procedimentos pedagógicos (GALATTI et al., 2014) capazes de atender o indivíduo em sua integralidade, perpassando por vivências que vão além dos aspectos técnicotáticos da ação, a partir da promoção de valores, atitudes e modos de comportamento que circundam o ambiente esportivo, indispensáveis no processo de formação humana (LEONARDI et al., 2014; REVERDITO et al., 2018; LEONARDI; BERGER; REVERDITO, 2019).

Quanto ao lazer, para além de políticas públicas que propiciem o acesso democrático aos espaços, equipamentos e seus conteúdos, faz-se necessário pensar políticas de formação de pessoal para atuarem nesses espaços (MARCELLINO et al. 2007b; MARIANO; MARCELLINO; 2011). A partir das observações in loco realizadas no presente estudo, constatou-se que os aparelhos disponíveis em espaços que apresentavam ambientes de conservação e manutenção raramente eram frequentados por aqueles adolescentes que apresentam histórico de conduta infracional. Este fato nos remete à hipótese do não pertencimento concebido por 
esses sujeitos, marginalizados dentro da sua própria comunidade. É nesse cenário que a mediação por animadores socioculturais (profissionais advindos das áreas da Pedagogia, Educação Física, Hotelaria, Turismo, dentre outros) torna-se relevante, uma vez que pode propiciar a diversificação dos conteúdos do lazer, a democratização da utilização dos espaços pela comunidade e influenciar na conservação dos equipamentos, através da interação e sensibilização com seu público.

Os desafios para a implementação de políticas públicas de inclusão pelo esporte e lazer para juventude perpassam por questões relacionadas ao "reconhecimento desses fenômenos como direitos garantidos enquanto instrumentos de educação e humanização", a "garantia de espaços com infraestrutura e segurança que oportunizem o desenvolvimento humano" e uma "rede de convívio social e serviços que fortaleçam os vínculos com a população jovem, em especial, aqueles envolvidos com atos infracionais" (NORONHA, 2009). Para a autora, esses desafios tornam-se imprescindíveis para a articulação de políticas públicas para a população jovem em contextos de vulnerabilidade, por carregarem princípios de intervenção socioeducativa e gestão participativa.

Dos equipamentos existentes nos bairros investigados, excluindo os que estão em estado de abandono e os localizados nas escolas municipais e estaduais, um número considerável $(n=11)$ é mantido pela comunidade local, através da organização de seus moradores ante a escassez de políticas. A pesquisa sinaliza que esses espaços são ocupados pela população adulta, que de certa forma se organiza para dispor dos materiais necessários à prática. Nesse sentido, sem a organização de políticas públicas voltadas ao esporte e ao lazer, a população jovem desses bairros acaba por não ocupar os poucos espaços disponíveis nas comunidades, cerceando ainda mais suas trajetórias.

Diante dos direitos renegados pelo poder público e estigmatizado pela sua própria comunidade, o adolescente em conflito com a lei busca seu pertencimento a partir do convívio com seus pares, que, por sua vez, já apresentam histórico de conduta infracional (JUNQUEIRA; JACOBY, 2006; TEJADAS, 2008; JIMENEZ; MARQUES, 2018; OLIVEIRA; TURECK, 2019; KOSTULSKI et al., 2019). Desta forma, aquele que em toda sua trajetória foi invisível aos olhos do Estado e da sociedade, no anseio de ocupar espaço de protagonismo, acaba por trilhar caminhos que se configuram como fator de risco ao cometimento de ato infracional. Surpreendentemente, somente a partir de tais condutas esses adolescentes tornam-se visíveis frente às políticas de atendimento secundárias e terciárias, alcançando o tão sonhado protagonismo, mesmo que de forma pejorativa.

$\mathrm{Na}$ contemporaneidade, não cabe conceber isoladamente as políticas de esporte e lazer como antídotos contra todos os males relacionados à vulnerabilidade social de jovens (MELO, 2005; HECKTHEUER, 2012; STIGGER; THOMASSIM, 2013). Porém, "se não utilizarmos em função da qualidade de vida das pessoas e para transformação dos modos de produção e reprodução da vida social, perderemos a oportunidade histórica de construir uma sociedade justa e igualitária" (NOGUEIRA, 2011, p. 114), oferecendo a oportunidade de enfrentar as adversidades e ressignificar os modos de vida. 
Considerando que o ato infracional é um fenômeno social e necessita ser entendido sobre diferentes prismas da ciência (OLIVERA; OLIVEIRA, 2019), urge a necessidade de concebermos essa problemática não só como responsabilidade do Estado, mas também, envidar esforços da sociedade e comunidade acadêmica a fim de lançar proposições que se configurem como fatores protetivos à conduta infracional.

\section{CONCLUSÃO}

O percurso dos adolescentes em conflito com a lei está marcado pela ausência de oportunidades de acesso ao esporte e ao lazer. À mercê da efetivação de políticas públicas que os considerem atores sociais, estes sujeitos são furtados de seus direitos fundamentais que Ihes oportunizem ressignificar suas trajetórias, a partir de ambientes que favoreçam os aspectos de resiliência.

Ante ao levantamento dos espaços, equipamentos e conteúdos de esporte e lazer disponibilizados pelo poder público nos bairros investigados, além da criação de novos espaços e a manutenção dos poucos equipamentos existentes, urge a necessidade da elaboração de propostas que propiciem a oferta de conteúdos diversificados de esporte e lazer à população jovem dessas comunidades. Ao considerar que o acesso ao esporte e ao lazer, a partir de um tratamento pedagógico adequado, pode propiciar ambientes favoráveis para o desenvolvimento positivo de adolescentes, é assertivo afirmar que, no contexto investigado, a falta de acesso a essas políticas pode se configurar como possível fator de risco ao cometimento de ato infracional.

Ao compor o rol de pesquisas dedicadas a elucidar os diversos fatores de risco e proteção relacionados ao cometimento de ato infracional, este estudo faz uma abordagem contextual. $\mathrm{O}$ contexto em que o sujeito estava inserido ante ao cometimento do ato infracional, que o levou à situação de cumprimento de medida socioeducativa, coloca em evidência fatores de risco à reincidência, uma vez que o adolescente retorna à sua comunidade.

Assim, este estudo oferece subsídios ao poder público no que tange à destinação de recursos para a efetivação das políticas de esporte e lazer à população jovem. Especificamente no contexto pesquisado, vislumbra-se que os resultados agucem o interesse dos gestores em garantir tais políticas ao adolescente em conflito com a lei, a partir da elaboração do Plano Municipal de Esporte e Lazer do Município de Cuiabá e Plano Estadual de Esporte e Lazer do Estado de Mato Grosso. Também, o fortalecimento das práticas de esporte e lazer nos programas que executam as medidas socioeducativas em meio aberto e fechado no Estado.

A natureza contextual deste estudo exigiu a inserção em um único município. Logo, o alcance dos resultados apresentados deverá considerar as características do contexto. Assim, faz-se necessária a produção de novos estudos que investiguem in loco os contextos dos quais são advindos esses adolescentes em cumprimento de medida socioeducativa de internação em outros municípios, a fim de constatar a oferta de espaços, equipamentos e conteúdos de esporte e lazer. 


\section{REFERÊNCIAS}

ANDRADE, Carolina Paes de; MARCELLINO, Nelson Carvalho. O lazer, a periferia da metrópole e os jovens: algumas relações. Licere, v. 14, n. 2, p. 1-17, jun. 2011. Disponível em: https://periodicos.ufmg.br/index.php/licere/article/view/773/574. Acesso em: 14 jan. 2020.

ASSIS, Simone Gonçalves de; CONSTANTINO, Patrícia. Perspectivas de prevenção da infração juvenil masculina. Ciência \& Saúde Coletiva, v. 10, n. 1, p. 81-90, jan./mar. 2005. Disponível em: http://www.scielo.br/pdf/csc/v10n1/a08v10n1.pdf. Acesso em: 19 fev. 2019.

BAZON, Marina Resende; SILVA, Jorge Luiz da; FERRARI, Renata Martins. Trajetórias escolares de adolescentes em conflito com a lei. Educação em Revista, v. 29, n. 2, p. 175199, jun. 2013. Disponível em: http://www.scielo.br/pdf/edur/v29n2/08.pdf. Acesso em: 12 abr. 2019.

BRASIL. Constituição da República Federativa do Brasil. Brasília, DF: Senado Federal: Centro Gráfico, 1988. 292 p.

BRASIL. Lei $n^{\circ} 8.069$, de 13 de julho de 1990. Dispõe sobre o Estatuto da Criança e do Adolescente e dá outras providências. Diário Oficial da União, Brasília, 13 de jul. de 1990. Disponível em: http://www.planalto.gov.br/ccivil_03/leis/l8069.htm. Acesso em: 20 jan. 2020.

BRASIL. Secretaria Nacional dos Direitos da Criança e do Adolescente. Relatório Anual do SINASE 2017. Brasília, 2019. Disponível em: https://www.gov.br/mdh/pt-br/navegue-portemas/crianca-e-adolescente/LevantamentoAnualdoSINASE2017.pdf/view. Acesso em: 29 fev. 2020.

CARNEIRO, Kleber Tuxen et al. Sobre lazer e possibilidades formativas em adolescentes que cumprem medidas socioeducativas. Pensar a Prática, v. 19, n. 4, p. 867-880, out./dez. 2016. Disponível em: https://www.revistas.ufg.br/fef/article/view/39672/pdf. Acesso em: 07 jan. 2019.

CONCEIÇÃO, Willian Lazaretti da. Lazer e adolescente em privação de liberdade: um diálogo possível? 2012. 145f. Dissertação (Mestrado em Educação) - Programa de Pós-Graduação em Educação, Universidade Federal de São Carlos, São Carlos/SP, 2012. Disponível em: https://repositorio.ufscar.br/bitstream/handle/ufscar/2630/4535. pdf? sequence=1\&isAllowed=y. Acesso em: 27 jan. 2019.

COSCIONI, Vinicius et al. Significados do mundo do crime para adolescentes em medida socioeducativa de internação, Brasil. Revista Latinoamericana de Ciencias Sociales, Niñes e Juventud, v. 17, n. 2, p. 1-20, jul./dez. 2019. Disponível em: http:// revistaumanizales.cinde.org.co/rlcsnj/index.php/Revista-Latinoamericana/article/ view/3790/1020. Acesso em: 23 mar. 2020.

DIAS, Aline Fávaro; ONOFRE, Elenice Maria Cammarosano. A relação do jovem em conflito com a lei e a escola. Impulso, v. 20, n. 49, p. 31-42, jan./jun. 2010. Disponível em: https:// www.metodista.br/revistas/revistas-unimep/index.php/impulso/article/view/870/471. Acesso em: 21 set. 2019.

DIB, Marina Azôr; BAZON, Marina Rezende; SILVA, Jorge Luiz da. Família e conduta infracional na adolescência: revisão sistemática da literatura. Perspectivas em Psicologia, v. 16, n. 1, p.142-159, jan./jun. 2012. Disponível em: http://www.seer.ufu.br/index.php/ perspectivasempsicologia/article/view/27553/15107. Acesso em: 15 nov. 2019.

FEIJÓ, Maria Cristina; ASSIS, Simone Gonçalves. O contexto de exclusão social e de vulnerabilidade de jovens infratores e de suas famílias. Estudos de Psicologia, v. 9, n. 1 , p. 157-166, abr. 2004. Disponível em: http://www.scielo.br/pdf/epsic/v9n1/22391.pdf. Acesso em: 18 out. 2019. 
FRANCO, Mariana Guedes de Oliveira; BAZON, Marina Rezende. Percurso e experiência escolar de adolescentes em conflito com a lei: trajetórias possíveis. Educação em Revista, v. 35, p. e18393, 2019. Disponível em: http://www.scielo.br/pdf/edur/v35/1982-6621-edur35-e183939.pdf. Acesso em: 05 jan. 2020.

GALATTI, Larissa Rafaela et al. Pedagogia do Esporte: tensão na ciência e o ensino dos Jogos Esportivos Coletivos. Revista da Educação Física/UEM, v. 25, n. 1, p. 153-162, 2014. Disponível em: http://www.scielo.br/pdf/refuem/v25n1/1983-3083-refuem-25-01-00153. pdf. Acesso em: 18 jan. 2019.

GALLO, Alex Eduardo; WILLIAMS, Lúcia Cavalcanti de Albuquerque. Adolescentes em conflito com a lei: uma revisão dos fatores de risco para a conduta infracional. Psicologia: Teoria e Prática, v.7, n.1, p.81-95, 2005. Disponível em: http://pepsic.bvsalud.org/pdf/ptp/ v7n1/v7n1a07.pdf. Acesso em: 23 fev. 2019.

GALLO, Alex Eduardo; WILLIAMS, Lúcia Cavalcant de Albuquerque. A escola como fator de proteção à conduta infracional de adolescentes. Cadernos de Pesquisa, v. 38, n. 133, p. 41-59, jan./abr. 2008. Disponível em: http://www.scielo.br/pdf/cp/v38n133/a03v38n133.pdf. Acesso em: 16 nov. 2019.

GIL, Antônio Carlos. Métodos e Técnicas de Pesquisa Social. 6 ed. São Paulo: Atlas 2008.

HECKTHEUER, Luiz Felipe Alcantara. Esporte e segurança em uma "sociedade de projetos". Motrivivência, v. 24, n. 38, p. 98-107, jun. 2012. Disponível em: https://periodicos. ufsc.br/index.php/motrivivencia/article/view/2175-8042.2012v24n38p98/22966. Acesso em: 25 nov. 2019.

IBGE. Cidades@. 2010. Disponível em: https://cidades.ibge.gov.br/brasil/mt/cuiabal panorama. Acesso em: 19 fev. 2020.

IBGE.Cidades@2020.Disponível em: https://cidades.ibge.gov.br/brasil/mt/cuiaba/ pesquisa/37/30255. Acesso em: 19 fev. 2020.

JIMENEZ, Luciene; ANDRADE, Elisa Meireles; BIANCHINI, Luciane Guimarães Batistella. Uso de drogas e ato infracional: Revisão integrativa de artigos brasileiros. Revista Latinoamericana de Ciencias Sociales, Niñes y Juventud, v.14, n. 2, p. 939-955, 2016. Disponível em: http://www.scielo.org.co/pdf/rlcs/v14n2/v14n2a05.pdf. Acesso em: 16 jan. 2020.

JIMENEZ, Luciene; FRASSETO, Flávio Américo. Face da morte: a lei em conflito com o adolescente. Psicologia e Sociedade, v. 27, n. 2, p. 404-414, 2015. Disponível em: https:// www.scielo.br/pdf/psoc/v27n2/1807-0310-psoc-27-02-00404.pdf. Acesso em: 10/08/2020.

JIMENEZ, Luciene; MARQUES, Vanda Regina. Revisão integrativa sobre a prática infracional na adolescência (2005/2014). Estudos da Psicologia, v. 23, n. 2, p. 111-121, abr./jun. 2018. Disponível em: http://pepsic.bvsalud.org/pdf/epsic/v23n2/a03v23n2.pdf. Acesso em: 09 jan. 2020.

JUNQUEIRA, Maíz Ramos; JACOBY, Márcia. O olhar dos adolescentes em conflito com a lei sobre o contexto social. Revista Textos e Contextos, v. 5, n. 2, p. 1-18, dez. 2006. Disponível em: http://revistaseletronicas.pucrs.br/fass/ojs/index.php/fass/article/ view/1036/815. Acesso em: 13 fev. 2019.

KOSTULSKI, Camila Almeida et al. Adolescência, violência e invisibilidade social: uma revisão crítica a partir da história de Sandro. Revista Sociais \& Humanas, v. 32, n. 3, p. 161-172, 2019. Disponível em: https://periodicos.ufsm.br/sociaisehumanas/article/ view/26823/pdf. Acesso em: 25 fev. 2020. 
LEONARDI, Thiago José et al. Pedagogia do esporte: indicativos para o desenvolvimento integral do indivíduo. Revista Mackenzie de Educação Física e Esporte, v. 13, n. 1, p. 41-58, ago. 2014. Disponível em: http://editorarevistas.mackenzie.br/index.php/remef/article/ view/3613. Acesso em: 09 set. 2019.

LEONARDI, Thiago José; BERGER, Artur Goulart; REVERDITO, Riller Silva. Esporte Contemporâneo e os Novos Desafios à Pedagogia do Esporte. In: BETTINE, Marco; GUTIERREZ, Gustavo Luis (org.). Esporte e sociedade: um olhar a partir da globalização. São Paulo: IEA-USP, 2019. p. 254-269. Disponível em: http://www.livrosabertos.sibi.usp.br/ portaldelivrosUSP/catalog/view/422/375/1493-1. Acesso em: 17 mar. 2020.

MACHADO, Gisele Viola; GALATTI, Larissa Rafaela; PAES, Roberto Rodrigues. Pedagogia do esporte e projetos sociais: interlocuções sobre a prática pedagógica. Movimento, v. 21, n. 2, p.405-418, abr./jun. 2015. Disponível em: https://seer.ufrgs.br/Movimento/article/ view/48275/34216. Acesso em: 22 fev. 2019.

MARCELLINO, Nelson Carvalho. Estudos do Lazer: uma introdução. Campinas: Autores Associados, 1996.

MARCELLINO, Nelson Carvalho. Introdução - apontamentos para a elaboração de um repertório de atividades de recreação e lazer por ambientes. In: MARCELLINO, Nelson Carvalho (org.). Lazer e recreação: repertório de atividades por ambientes. Campinas, SP: Papirus, 2010. V. II. p. 9-14.

MARCELLINO, Nelson Carvalho et al. Espaços e Equipamentos de Lazer em Região Metropolitana: o caso da RMC - Região Metropolitana de Campinas. Curitiba: OPUS, 2007a. Disponível em: http://www.vitormarinho.ufsc.br/bitstream/handle/123456789/244/ espacosEquipamentos. pdf? sequence=1\&isAllowed=y. Acesso em: 28 jan. 2020.

MARCELLINO, Nelson Carvalho et al. Políticas Públicas de Lazer - formação e desenvolvimento de pessoal: os casos de Campinas e Piracicaba-SP. Curitiba: OPUS, 2007b. Disponível em: https://repositorio.ufsc.br/bitstream/handle/123456789/128012/ politicasPublicas.pdf?sequence=1. Acesso em: 28 jan. 2020.

MARCELLINO, Nelson Carvalho; BARBOSA, Felipe Soligo; MARIANO, Stéphanie Helena. As cidades e o Acesso aos Espaços e Equipamentos de Lazer. Impulso, Piracicaba, v. 17, n. 44, p. 55-66, 2006.

MARIANO, Stéphanie Helena; MARCELLINO, Nelson Carvalho. Animação sociocultural em cidades pequenas da região metropolitana de campinas (SP). Revista Mackenzie de Educação Física e Esporte, v. 10, n. 2, p. 74-86, 2011. Disponível em: http:// editorarevistas.mackenzie.br/index.php/remef/article/view/3517. Acesso em: 8 set. 2019.

MARTINS, Mayra Costa; PILLON, Sandra Cristina. A relação entre a iniciação do uso de drogas e o primeiro ato infracional entre os adolescentes em conflito com a lei. Cadernos de Saúde Pública, v. 24, n. 5, p. 1112-1120, mai. 2008. Disponível em: http://www.scielo.br/ pdf/csp/v24n5/18.pdf. Acesso em: 2 mar. 2020.

MARUSCHI, Maria Cristina; ESTEVÃO, Ruth; BAZON, Marina Rezende. Conduta infracional na adolescência: fatores associados e risco de reincidência. Arquivos Brasileiros de Psicologia, v. 66, n. 2, p. 82-99, 2014. Disponível em: http://pepsic.bvsalud.org/pdf/arbp/ v66n2/07.pdf. Acesso em: 15 jun. 2019.

MELO, Marcelo Paulo de. Esporte e juventude pobre: políticas públicas de lazer na Vila Olímpica da Maré. Campinas: Autores Associados, 2005. 
MORAES, Paulo Mateus de et al. O programa segundo tempo na região Centro-Oeste: continuidade e estrutura burocrática do esporte nos municípios. Revista Brasileira Ciência e Movimento, v. 25, n. 1, p. 129-140, 2017. Disponível em: https://portalrevistas.ucb.br/ index.php/RBCM/article/view/7476/pdf. Acesso em: 12 jan. 2020.

MORAIS, Normanda Araújo de; RAFFAELLI, Marcela; KOLLER, Sílvia Helena. Adolescentes em situação de vulnerabilidade social e o continuum risco-proteção. Avances em Psicología Latinoamericana, v. 30, n. 1, p. 118-136, 2012. Disponível em: https://pdfs. semanticscholar.org/a8a4/465684472694e931f41640679e59250f0872.pdf. Acesso em: 14 mar. 2020.

NARDI, Fernanda Ludke; DELL'AGLIO, Débora Dalbosco. Delinquência juvenil: uma revisão teórica. Acta Colombiana de Psicologia, v. 13, n. 2, p. 69-77, 2010. Disponível em: http:// www.scielo.org.co/pdf/acp/v13n2/v13n2a07.pdf. Acesso em: 11 jan. 2020.

NOGUEIRA, Quéfren Weld Cardoso. Esporte, desigualdade, juventude e participação.

Revista Brasileira de Ciências do Esporte, v. 33, n. 1, p. 103-117, jan./mar. 2011.

Disponível em: http://www.scielo.br/pdf/rbce/v33n1/a07v33n1.pdf. Acesso em: 5 mar. 2020.

NORONHA, Vânia. Pensando sobre políticas públicas de lazer para juventudes em contexto de vulnerabilidade social: contribuições a partir de pesquisa em Ribeirão das Neves/Minas Gerais. In: NORONHA, Vânia (org.). Belo Horizonte: Editora, 2009. Disponível em: http://vitormarinho.ufsc.br/bitstream/handle/123456789/236/pensandoSobrePoliticas. pdf? sequence=1\&isAllowed=y. Acesso em: 14 fev./2020.

NUNES, Mikaella Cristina Antunes; ANDRADE, Anne Graça de Sousa; MORAIS, Normanda Araújo de. Adolescentes em conflito com a lei e família: um estudo de revisão sistemática da literatura. Contextos Clínicos, v. 6, n. 2, p. 144-156, jul./dez. 2013. Disponível em: http:// pepsic.bvsalud.org/pdf/cclin/v6n2/v6n2a08.pdf. Acesso em: 10 jun. 2019.

OLIVEIRA, Renata Hoeflich Damaso de; TURECK, Lucia Terezinha Zanato. A invisibilidade social e a prática do ato infracional na adolescência: possíveis correlações. Revista

Educação e Cultura Contemporânea, v. 16, n. 45, p. 460-477, 2019. Disponível em: http:// periodicos.estacio.br/index.php/reeduc/article/view/4332/47966102. Acesso em: 8 mar. 2020.

OLIVEIRA, Ueliton Peres de et al. Esporte e lazer no plano individual de atendimento de adolescentes em cumprimento de medida socioeducativa de internação. Movimento, $\mathrm{n}$. 26, p. e26054, jan./dez. 2020. https://seer.ufrgs.br/Movimento/article/view/101588/57849. Acesso em: 2 ago. 2020.

OLIVERA, Raul Angel Carlos; OLIVEIRA, Ueliton Peres de. Modelo simples de crime racional: modelagem econométrica do perfil socioeconômico de adolescentes em conflito com a lei. In: FERNANDES, Maria Nilvane; COSTA, Ricardo Peres da. (org.). Coletânea Socioeducação no Brasil: intersetorialidade, desafios e referências para o atendimento. Curitiba: Nova Práxis, 2019. v. 4. p. 214-232.

PIZANI, Rafael Stein; AMARAL, Silvia Cristina Franco; PAES, Roberto Rodrigues. Esporte e lazer: diálogos possíveis à luz da pedagogia do esporte. Licere, v. 15, n. 3, p. 1-18, set. 2012. Disponível em: https://periodicos.ufmg.br/index.php/licere/article/view/717/518. Acesso em: 16 jul. 2019.

POLETTO, Michele; KOLLER, Silvia Helena. Contextos ecológicos: promotores de resiliência, fatores de risco e de proteção. Estudos de Psicologia, v. 25, n. 3, p. 405-416, jul./set. 2008. Disponível em: http://www.scielo.br/pdf/estpsi/v25n3/a09v25n3.pdf. Acesso em: 27 ago. 2019. 
REVERDITO, Riller Silva. Pedagogia do esporte e modelo bioecológico do desenvolvimento humano: indicadores para avaliação de impacto em programa socioesportivo. 2016. 209f. Tese (Doutorado em Educação Física). Programa de Pósgraduação em Educação Física, Universidade Estadual de Campinas, Campinas, 2016. Disponível em: http://repositorio.unicamp.br/bitstream/REPOSIP/322128/1/Reverdito RillerSilva_D.pdf. Acesso em: 26 mar. 2018.

REVERDITO, Riller Silva et al. Espaços e equipamentos disponíveis para o lazer: possibilidades da criança ao jogo na cidade de Hortolândia-SP. Licere, v. 15, n. 3, p. 1-24, set. 2012. Disponível em: https://periodicos.ufmg.br/index.php/licere/article/view/714/515. Acesso em: 11 jan. 2020.

REVERDITO, Riller Silva et al. O esporte na ecologia do desenvolvimento humano: desafios da pesquisa e intervenção no Brasil. In: BENTO, Jorge Olímpio et al. (org.). Cuidar da casa comum: Da natureza, da vida, da humanidade. Oportunidades e responsabilidades do Desporto e da Educação Física. Belo Horizonte: Casa da Educação Física, 2018. v. 1. p. 203-215. Disponível em: http://cev.org.br/arquivo/biblioteca/4041560.pdf. Acesso em: 26 jan. 2020.

SAMPIERI, Roberto Hernández; COLLADO, Carlos Fernández; LUCIO. María del Pilar Baptista. Metodologia de pesquisa. São Paulo: McGraw-Hill, 2006.

SANIOTO, Henrique. Contribuindo para a formação humana dos adolescentes da FEBEM por meio da Ginástica Geral. 2005. 198f. Dissertação (Mestrado em Educação Física). Programa de Pós-graduação em Educação Física, Universidade Estadual de Campinas, Campinas, 2005. Disponível em: http://repositorio.unicamp.br/handle/ REPOSIP/274914. Acesso em: 18 jan. 2019.

SANTINI, Rita de Cássia Giraldi. Dimensões do lazer e da recreação. São Paulo: Angelotti, 1993. $101 \mathrm{p}$.

SILVA, Fábio Silvestre et al. Futebol Libertário: compromisso social na medida. Psicologia Ciência e Profissão, v. 28, n. 4, p. 832-845, out. 2008. Disponível em: http://www.scielo.br/ pdf/pcp/v28n4/v28n4a14.pdf. Acesso em: 12 jan. 2019.

SILVA, Jorge Luiz da; BAZON, Marina Rezende. Revisão sistemática de estudos sobre os aspectos escolares relacionados ao cometimento de delitos. Psicologia em Revista, v. 21, n. 2, p. 273-292, ago. 2015. Disponível em: http://pepsic.bvsalud.org/pdf/per/v21n2/ v21n2a05.pdf. Acesso em: 19 set. 2019.

STIGGER, Marco Paulo; THOMASSIM, Luis Eduardo. Entre o "serve" e o "significa": uma análise sobre expectativas atribuídas ao esporte em projetos sociais. Licere, v. 16, n. 2, p. 1-33, jun. 2013. Disponível em: https://periodicos.ufmg.br/index.php/licere/article/ view/656/457. Acesso em: 25 fev. 2020.

TEJADAS, Silvia da Silva. Juventude e Ato Infracional. Porto Alegre: EDIPUCRS, 2008.

TIELLET, Maria do Horto Salles et al. Ações de extensão em um centro de atendimento socioeducativo do Estado de Mato Grosso. EDUCA - Revista Multidisciplinar em Educação, v. 4, n. 9, p. 65-78, set./dez. 2017. Disponível em: http://www.periodicos.unir.br/ index.php/EDUCA/article/view/2132/2141. Acesso em: 17 jan. 2019. 
Abstract: This exploratory and descriptive study aims to identify sports and leisure spaces, equipment and contents of a municipality in the Brazilian state of Mato Grosso with higher incidence of adolescents sentenced to socio-educational internment in 2017 and 2018. Data were provided by the State Management of the Children and Adolescents Information System (SIPIA). On-site observation was carried out in eight neighborhoods, using predefined analytical categories for field diary records. The results point to scarce offer of sport and leisure spaces, equipment and content in those communities. In view of this scenario, the study concludes that the lack of access to sports and leisure policies is seen as a possible risk factor for committing infractions in the context researched, in addition to exposing young people to the same risk when they return to their communities.

Keywords: Adolescent. Sports. Leisure activities. Child advocacy.

Resumen: Este estudio exploratorio y descriptivo tiene por objetivo identificar los espacios, equipos y contenidos de deporte y recreación de un municipio del estado de Mato Grosso que tiene mayor incidencia de adolescentes en cumplimiento de medida socioeducativa de internación durante los años 2017 y 2018. Los datos fueron puestos a disposición por la Administración Estatal del Sistema de Información para Infancia y Adolescencia (SIPIA). Se realizaron observaciones in situ en ocho barrios, utilizando categorías de análisis predefinidas para registros en diario de campo. Los resultados demuestran la escasa oferta de espacios, equipos y contenidos de deporte y recreación que se ofrece a los adolescentes de esas comunidades. Ante este escenario, la falta de acceso a políticas de deporte y recreación puede configurarse como posible factor de riesgo para cometer infracciones en el contexto investigado, además de exponer a los jóvenes al mismo riesgo cuando regresan a la comunidad.

Palabras clave: Adolescente. Deportes. Actividades Recreativas. Defensa del niño y el adolescente. 


\section{LICENÇA DE USO}

Este é um artigo publicado em acesso aberto (Open Access) sob a licença Creative Commons Atribuição 4.0 Internacional (CC BY 4.0), que permite uso, distribuição e reprodução em qualquer meio, desde que o trabalho original seja corretamente citado. Mais informações em: http://creativecommons.org/licenses/by/4.0

\section{CONFLITO DE INTERESSES}

Os autores declararam que não há conflito de interesses neste trabalho.

\section{CONTRIBUIÇÕES AUTORAIS}

Ueliton Peres de Oliveira: Realizou a coleta dos dados; analisou os dados e desenvolveu o documento no formato do artigo;

Willian Lazaretti da Conceição: Realizou a revisão do documento no formato de artigo; participou da análise e discussão dos dados; Colaboração com o referencial teórico;

José Tarcísio Grunennvaldt: Realizou a revisão do documento no formato de artigo; participou da análise e discussão dos dados;

Raul Angel Carlos Olivera: Realizou a revisão do documento no formato de artigo; participou da análise e discussão dos dados; Colaboração com o referencial teórico;

Riller Silva Reverdito: Orientou o desenvolvimento do artigo; colaborou com a metodologia, análise e discussão dos dados.

\section{FINANCIAMENTO}

Centro de Desenvolvimento de Pesquisa em Políticas de Esporte e de Lazer da Rede Cedes do Estado de Mato Grosso; Ministério da Cidadania, Secretaria Especial do Esporte/Secretaria Nacional de Esporte, Educação, Lazer e Inclusão Social (SNELIS);

Centro Interdisciplinar de Pesquisas em Esporte e Exercício Físico (CIPEEF), Universidade do Estado de Mato Grosso.

\section{ÉTICA EM PESQUISA}

Pesquisa submetida ao Comitê de Ética em Pesquisa - CEP/SAÚDE/UFMT (CAAE: 03382918.9.0000.8124). Aprovada no dia 26 de dezembro de 2018, sob parecer $n^{\circ}$ 3.102.411.

\section{COMO REFERENCIAR}

OLIVEIRA, Ueliton Peres de; CONCEIÇÃO, Willian Lazaretti da; GRUNNENVALDT, José Tarcísio; OLIVERA, Raul Angel Carlos; REVERDITO, Riller Silva. Adolescentes e conduta infracional: espaços, equipamentos e conteúdos de esporte e lazer. Movimento, v.26, p.26079, 2020. Disponível em: https://seer.ufrgs.br/Movimento/article/view/102733. Acesso em: [dia] [mês abreviado]. [ano]. DOI: https://doi.org/10.22456/1982-8918.102733

\section{RESPONSABILIBADE EDITORIAL}

Alex Branco Fraga*, Elisandro Schultz Wittizorecki*, Ivone Job*, Mauro Myskiw*, Raquel da Silveira* 
*Universidade Federal do Rio Grande do Sul, Escola de Educação Física, Fisioterapia e Dança, Porto Alegre, RS, Brasil 